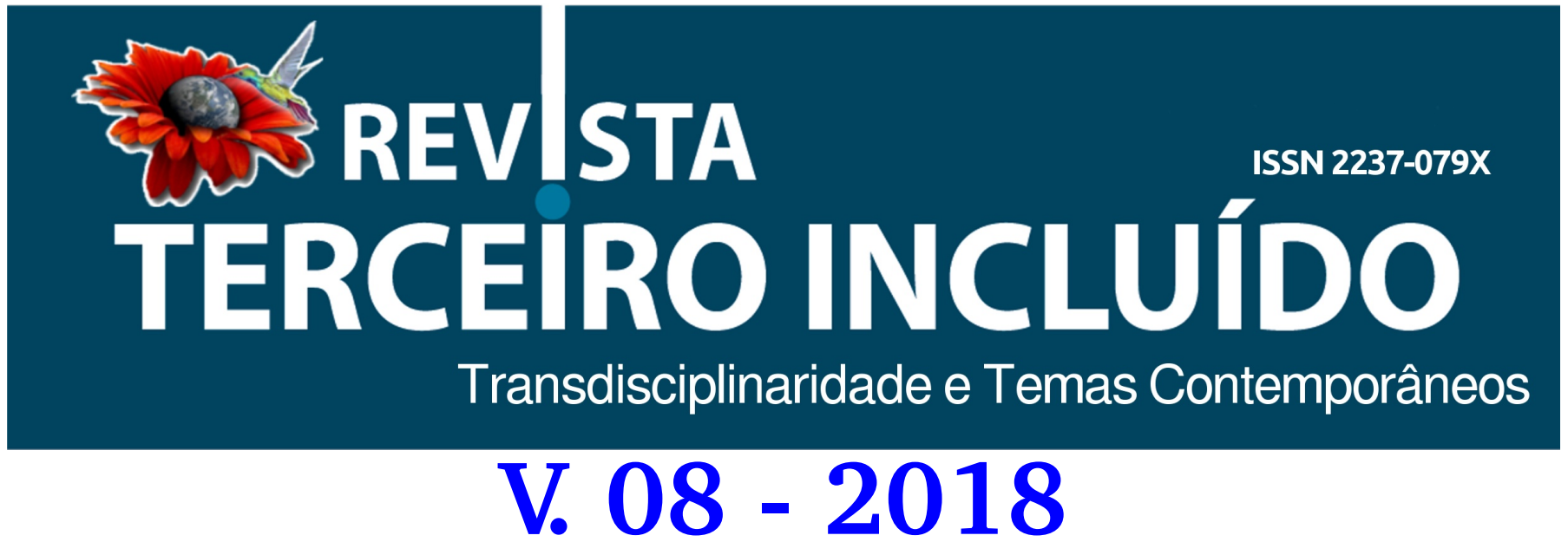

MOREIRA, Carolina Joly; BISPO, Marciléia Oliveira.

Políticas Públicas De Educação Ambiental No Brasil - Alguns Fatores De Desconstrução

pp. $49-61$

DOI: $10.5216 /$ teri.v8i1.51414 


\title{
POLÍTICAS PÚBLICAS DE EDUCAÇÃO AMBIENTAL NO BRASIL - ALGUNS FATORES DE DESCONSTRUÇÃO
}

\author{
POLÍTICAS PÚBLICAS DE EDUCACIÓN AMBIENTAL EN BRAZIL - \\ ALGUNOS FACTORES DE DESCONSTRUCIÓN
}

\section{PUBLIC POLICIES OF ENVIRONMENTAL EDUCATION IN BRAZIL - SOME DECONSTRUCTION FACTORS}

Carolina Joly MOREIRA ${ }^{1}$

Marciléia Oliveira BISPO

RESUMO: O presente trabalho busca apontar, através de revisão bibliográfica, o atual descolamento entre as prerrogativas legais que envolvem a Educação Ambiental em âmbito formal, e algumas práticas cotidianas da sociedade brasileira, resultando, paradoxalmente, em aumento da degradação ambiental em diversos aspectos, tanto no meio urbano como no meio rural. A título de motivações que podem estar contribuindo para que haja essa divergência, apontamos quatro fatores de influência: a dificuldade das familias em mudar hábitos, as práticas antipedagógicas governamentais, os conflitos epistemológicos na elaboração de políticas públicas e o tratamento dado ao tema nas licenciaturas e no ensino superior, de maneira geral. Como conclusão, ressaltamos o entendimento de que, apesar das dificuldades apontadas, ainda está nas políticas públicas o poder de transformação, mas é preciso haver respaldo e participação efetiva em cada sala de aula do país.

Palavras chave: Educação Ambiental formal; legislação; políticas públicas; degradação ambiental

RESUMEN: El presente trabajo busca apuntar, a través de revisión bibliográfica, el actual desprendimiento entre las prerrogativas legales que envuelven la Educación Ambiental en ámbito formal, y algunas prácticas cotidianas de la sociedad brasileña, resultando, paradójicamente, en aumento de la degradación ambiental en diversos aspectos, tanto en medio urbano como en el medio rural. A título de motivaciones que pueden estar contribuyendo a que haya esa divergencia, apuntamos cuatro factores de influencia: la dificultad de las familias en cambiar hábitos, las prácticas antipedagogicas gubernamentales, los conflictos epistemológicos en la elaboración de políticas públicas y el tratamiento dado al tema en las licenciaturas y en la enseñanza superior, de manera general. Como conclusión, resaltamos el entendimiento de que, a pesar de las dificultades señaladas, todavía está en las políticas públicas el poder de transformación, pero hay que haber respaldo y participación efectiva en cada aula del país.

Palabras claves: Educación Ambiental formal; legislación; políticas públicas; degradación ambiental

ABSTRACT: The presente work seek to point out, through bibliographic revision, the current desengagement between legal prerogatives which formal Environmental Education involves and some everyday praticals of Brazilian society, resulting, paradoxically, in environmental degradation increase in many aspects, as in urban as in the country side. As motivations that could be contribuiting for this derangement, we point out four influence factors: the difficulty of families to change their habits, the governmental anti-pedagogy practices, the epistemological conflicts in the elaboration of public policies and the treatment given to the subject in the degrees and in the higher education, in general way. As a conclusion, we emphasize the understandig that, although the highlighted difficulties, still in public policies the transformation power, but support and effective participation are necessary, in each classroom around the country.

Key words: scholar Environmental Education; legislation; public policies; environmental degradation

1 Pós doutoranda do Programa de Pós-graduação em Geografia da Universidade Federal do Tocantins (UFT), campus Porto Nacional, Doutora em Ambiente e Sociedade. Endereço: carolina_joly@hotmail.com

2 Professora do curso de Pós-graduação em Geografia da Universidade Federal do Tocantins (UFT), campus Porto Nacional, Doutora em Geografia. Endereço: marcileia@uft.edu.br 


\section{INTRODUÇÃO}

Em uma retrospectiva das últimas duas décadas deste século, se considerarmos como marco inicial das discussões sobre a prática da Educação Ambiental no Brasil a Conferência RIO 92, podemos perceber uma grande difusão das legislações relacionadas ao tema em todos os níveis de governo. Contudo, o start foi dado ainda em nossa Constituição Federal de 1988, em seu Artigo 225 do Capítulo VI - Do Meio Ambiente, Inciso VI, que destaca a necessidade de "promover a Educação Ambiental em todos os níveis de ensino e a conscientização pública para a preservação do meio ambiente" (BRASIL, 1988, p.146). Desde então, em cumprimento dos preceitos constitucionais, leis federais, decretos, constituições estaduais e leis municipais determina-se a obrigatoriedade da Educação Ambiental. Nos últimos dez anos, por exemplo, tornou-se comum os municípios brasileiros também terem suas políticas de Educação Ambiental contempladas em suas leis orgânicas.

Em 1999, assistimos na esfera federal a criação da Política Nacional de Educação Ambiental (Lei federal $n^{\circ} 9.795$, de 27/04/1999), regulamentada pelo Decreto federal $n^{\circ} 4.281$, de 25/06/2002, a qual foi seguida por muitas leis estaduais, reproduzindo as mesmas diretrizes da política nacional. A exceção foi o Estado do Pará, que já em 1990, portanto nove anos antes da criação da lei federal, aprovou sua lei estadual referente à promoção da Educação Ambiental em todos os níveis (Lei estadual $n^{\circ} 26.752$, de 29/06/1990).

A implementação dessa política, no caso dos estados, ficou dividida entre as Secretarias Estaduais de Educação, responsáveis pela Educação Ambiental formal, e as Secretarias Estaduais de Meio Ambiente, responsáveis pelo contingente não formal, refletindo a divisão adotada na esfera federal, na qual a implementação da Política ficou a cargo dos Ministérios da Educação (MEC) e do Meio Ambiente (MMA). Desde a publicação desta lei, outros esforços se seguiram no que tange a nossa legislação no âmbito dos dois ministérios, dentre os quais podemos destacar o Programa Nacional de Educação Ambiental-ProNEA (MEC/MMA) de 1994, a inclusão do tema transversal Meio Ambiente nos Parâmetros Curriculares Nacionais-PCN (MEC) em 1997, a Estratégia Nacional para Comunicação e Educação Ambiental-ENCEA (MMA), as Diretrizes Curriculares Nacionais para a Educação Ambiental (MEC), de 2012 e o Programa Nacional Escolas Sustentáveis (MEC), de 2013.

Para além de nossas leis e programas, há também os compromissos internacionais de apoio ao desenvolvimento da Educação Ambiental ratificados pelo Congresso Nacional Brasileiro, tornando-se, portanto, um comprometimento internacional. Dentre eles podemos destacar alguns como a Convenção da Diversidade Biológica (CDB) e a Convenção-Quadro das Nações Unidas sobre Mudanças Climáticas, ambas criadas durante a ECO 92. Dentre as Metas de Aichi ${ }^{3}$, por exemplo, uma das Conferências da CDB, realizada em 2010, colocou-se como meta número um o seguinte preceito: “em 2020, no mais tardar, as pessoas devem estar cientes dos valores da biodiversidade e do que podem fazer para conservá-la e para usá-la sustentavelmente" (CONVENÇÃO DA DIVERSIDADE

3 Durante a $10^{a}$ Conferência das Partes da Convenção sobre Diversidade Biológica (COP-10), realizada na cidade japonesa de Nagoya, Província de Aichi, foi aprovado o Plano Estratégico de Biodiversidade para o período de 2011 a 2020. Este plano, que serve de base para estratégias do sistema das Nações Unidas e parceiros envolvidos na gestão da biodiversidade, busca estabelecer ações concretas para deter a perda da biodiversidade planetária. 
BIOLÓGICA, 2010, p.01).

No mesmo período, especialmente na última década, passamos por grandes transformações sociais em todo o território brasileiro. No campo do ensino público tivemos, primeiramente, a ampliação de políticas públicas de inclusão escolar, através da obrigatoriedade da universalização do ensino, indo além do nível fundamental e alcançando também os ensinos infantil e médio (Lei federal $\mathrm{n}^{\circ} 12.061$, de 27/10/2009). Portanto, desde 2009, a educação básica (que compreende os níveis infantil, fundamental e médio) é obrigatoriamente ofertada de forma gratuita pela rede pública de ensino (dos 4 aos 17 anos de idade), além de também ser ofertada àqueles que não tiveram acesso na idade própria, através dos programas como o Educação de Jovens e Adultos (EJA), Educação Profissional e Educação Especial.

Segundo a Sinopse Estatística da Educação Básica de 2016 (INEP, 2016), em março de 2017 havia cerca de 48.817.479 milhões de estudantes matriculados em todos os níveis no Brasil, apesar das distorções provocadas pelas desigualdades regionais, sociais, raciais e pelo importante peso que ainda têm a repetência e a evasão escolar, como aponta Silva (2015, p.62). A universalização plena, então prevista para ser alcançada em 2016, ainda está longe de ser realidade, segundo Silva (2015, p.63), mas representa um contingente de $94,2 \%$ dos jovens em idade escolar, que, teoricamente, devem passar por experiências escolares onde o tema Meio Ambiente deve, obrigatoriamente, ser trabalhado. Os Parâmetros Curriculares Nacionais (PCN) preveem sua abordagem como tema transversal desde 1997.

Dentre as diretrizes do mais recente Plano Nacional de Educação (PNE 2014 - 2024), sancionado através de Lei Federal n¹3.005, de 25/06/2014, está contemplado, em seu artigo segundo, capítulo X, a seguinte normativa: “a promoção dos princípios do respeito aos direitos humanos, à diversidade e à sustentabilidade socioambiental." (BRASIL, 2014, p.43). O tema ambiental, portanto, está contemplado desde o ensino infantil até o ensino profissionalizante, nos diversos ciclos de aprendizado pelos quais estes jovens e adultos têm passado ou podem passar.

Quando analisamos o outro lado das salas de aula, o dos docentes, percebemos que obtivemos também nas últimas duas décadas deste século, o incentivo do poder público também à formação de professores, principalmente através de programas governamentais como o Programa Universidade para Todos (PROUNI), o Fundo de Financiamento ao Estudante do Ensino Superior (FIES) e a Universidade Aberta do Brasil (UAB), que dão incentivo às carreiras docentes.

O PROUNI consiste na concessão de bolsas de estudo integrais e parciais, em cursos de graduação e sequenciais de formação específica em instituições privadas de educação superior, dirigido aos estudantes vindos do ensino médio. Para concorrer às bolsas integrais, os candidatos devem comprovar renda per capita familiar máxima de três salários mínimos, além de realizarem o Exame Nacional de Ensino Médio (ENEM). Mas os professores da rede pública que não possuem licenciatura podem concorrer às vagas nos cursos de pedagogia e licenciaturas sem necessidade de comprovar renda.

O FIES é um programa de financiamento de cursos de graduação voltado para estudantes matriculados em instituições de ensino não gratuitas. Os candidatos necessitam de uma avaliação positiva através de processos conduzidos pelo MEC para serem contemplados. Os professores em efetivo exercício da docência na rede pública da educação básica, com jornada mínima de 20 horas 
semanais e regularmente matriculados em cursos de licenciatura podem solicitar o abatimento mensal de $1 \%$ do saldo devedor, conforme previsto no artigo 6º-B da Lei no 10.260/2001 (incluído pela Lei federal no 12.202/2010).

Já a UAB consiste em um sistema integrado por universidades públicas que utiliza a metodologia da educação a distância para oferecer cursos de nível superior àqueles que têm dificuldade de acesso à formação universitária, tendo

como objetivo expandir e interiorizar a oferta de cursos e programas de educação superior. Os professores que atuam na educação básica têm prioridade de formação, seguidos dos dirigentes, gestores e trabalhadores em educação básica dos estados, municípios e do Distrito Federal.

Outro destaque é o Programa Institucional de Bolsas de Iniciação à Docência (PIBID), que vem desempenhando importante papel na ambientação dos milhares de alunos das licenciaturas junto ao ambiente escolar ainda durante sua formação. Nesse período, é esperado que estes futuros professores, especialmente os das áreas de Geografia e Ciências, abordem temas ligados à Educação Ambiental. Há também instrumentos legais que tratam do tema junto ao ensino superior, como a própria Política Nacional de Educação Ambiental (BRASIL, 1999), o Programa Nacional de Educação Ambiental - ProNEA (BRASIL, 2005) e, mais recentemente, a Resolução n 2, de 15 de junho de 2012, que estabelece as Diretrizes Curriculares Nacionais para a Educação Ambiental - DCNEA (BRASIL, 2012).

Para Guerra \& Figueiredo (2014, p.110),

Assim, ao considerarmos o papel central do ensino superior nas universidades, na facilitação da construção do conhecimento e suas inúmeras funções e responsabilidades frente a uma sociedade mais justa, igualitária e ética, torna-se indiscutível sua importância na inserção da dimensão ambiental em suas diversas frentes de atuação (ensino, pesquisa, extensão e gestão), (...). (GUERRA \& FIGUEIREDO, 2014, p.110)

\section{FATORES DE DESCONSTRUÇÃO}

Apesar destas transformações no campo educacional e de todo o respaldo legal para o tratamento do tema ambiental em toda a rede de ensino do país há mais de uma década, assistimos ao aumento generalizado da degradação ambiental em nossos biomas, tanto no campo como nas cidades brasileiras, como se houvesse um profundo descolamento dos temas supostamente trabalhados em sala de aula e o cotidiano de milhões de brasileiros.

A sociedade brasileira, agora mais escolarizada, assiste calada ao aumento do desmatamento em áreas de expansão agrícola na região Norte do país, ao aumento da escassez hídrica de maneira generalizada em todo o território nacional (em um país detentor de oito grandes bacias hidrográficas), a perda diária de biodiversidade com a destruição de habitats e ao aumento da emissão de gases do efeito estufa através de práticas arcaicas como as queimadas, entre muitas outras ameaças. Em 2017, por exemplo, os focos de incêndio bateram o antigo recorde de 2007, quando foram contabilizados 94.516 focos em todo país. A declaração de Alberto Sertzer ${ }^{4}$, técnico responsável pelo

4 Publicado em: https://g1.globo.com/natureza/noticia/brasil-tem-mes-com-maior-numero-de-queimadas-da-historia.ghtml em 22/09/17. 
programa de monitoramento de queimadas do Instituto Nacional de Pesquisas Espaciais (INPE), ilustra bem esse paradoxo:

As unidades de conservação estão queimando excessivamente. E o que se vê é uma piora ao longo dos anos. Falta fiscalização, mas também punição. Os estados até se organizaram muito bem neste ano com protocolos, campanhas. Mas a população não levou isso em conta. Então não adianta todo o trabalho de educação.

A questão que se coloca é por que andamos nesta direção, se nos últimos anos investimos tanto na área mais sensível, segundo os especialistas, para provocar uma alteração da consciência ambiental em massa, que é a educação? Será que realmente não adianta? A seguir, apontamos quatro fatores que podem contribuir para essa percepção.

\section{HÁBITOS, CONSUMO E DESRESPONSABILIZAÇÃO}

O primeiro fator refere-se ao fato de que a mudança de mentalidade, por mais que seja mencionada no ambiente escolar, exige desafios pessoais e familiares que envolvem mudança de hábitos, sobretudo aqueles relacionados ao consumo. Nas últimas duas décadas, desde a estabilização da economia nacional, nossa sociedade foi impelida ao aumento generalizado do consumo, com disponibilidade de crédito e fácil acesso a bens de consumo em geral. Esse fator impactou diretamente a produção de resíduos sólidos no país, por exemplo, sem qualquer preocupação ambiental. Percebese que, de maneira geral, o princípio do poluidor-pagador, já previsto em nossa Constituição Federal de 1988, parece ainda não ter sido internalizado pelo brasileiro.

O dado que melhor ilustra essa condição é observado quando verificamos informações sobre a geração de resíduos sólidos em nossa sociedade do século XXI. Segundo a Associação Brasileira de Empresas de Limpeza Pública e Resíduos Especiais (ABRELPE), o Brasil tem hoje uma produção de resíduos sólidos por habitante por ano semelhante à de países desenvolvidos, mas ainda tem um padrão de descarte equivalente ao dos países pobres.

Segundo a última publicação do Panorama dos Resíduos Sólidos no Brasil (ABRELPE, 2016, p.14):

\footnotetext{
A disposição final dos resíduos sólidos urbanos coletados demonstrou piora comparado ao índice do ano anterior, de $58,7 \%$, para $58,4 \%$ ou 41,7 milhões de toneladas enviadas para aterros sanitários. O caminho da disposição inadequada continuou sendo trilhado por 3.331 municípios brasileiros [dos atuais 5.570], que enviaram mais de 29,7 milhões de toneladas de resíduos, correspondentes a $41,6 \%$ do coletado em 2016, para lixões ou aterros controlados, que não possuem o conjunto de sistemas e medidas necessários para proteção do meio ambiente contra danos e degradações (ABRELPE, 2016, p.14)
}

Ainda sobre esse tema, observamos que algumas campanhas e projetos pedagógicos nas escolas que abordam a reciclagem de resíduos sólidos, também pecam pela falta de pensamento crítico a respeito do consumismo, que deve ser elucidado e combatido. Essa visão pode, inclusive, dar a falsa ideia de que estamos fazendo a nossa parte e, por isso, podemos até aumentar nosso consumo porque praticamos a reciclagem de materiais. Trajber (2007, p.147), ao descrever uma experiência de reciclagem vivenciada por uma escola conta que: 
[Os alunos] Foram então pesquisar como outras escolas estavam trabalhando a questão do consumo e do lixo. Descobriram o Projeto Escola desenvolvido por algumas escolas em parceria com a indústria de reciclagem, para concorrer a computadores com a coleta de latinhas. Em seguida, [...] os realizadores desse projeto limitavam o processo pedagógico a uma finalidade utilitarista. Além disso, os jovens perceberam que para ganhar os equipamentos prometidos, as crianças de escolas pobres passavam a catar latas de alumínio nos lixos e nas ruas, enquanto as de escolas abastadas pediam aos seus familiares para consumirem mais bebidas em latas de alumínio. (TRAJBER, 2007, p.147)

Além de ainda não ter uma preocupação ambiental, falta também a experiência de uma condição cidadã de fato, onde direitos (ao meio ambiente equilibrado) e deveres (de minimizar ao máximo os impactos ambientais cotidianos das famílias) fossem estabelecidos, compartilhados e vivenciados.

\section{Para Jacobi (2003, p.192),}

A postura de dependência [do poder público] e de desresponsabilização da população decorre principalmente da desinformação, da falta de consciência ambiental e de um déficit de práticas comunitárias baseadas na participação e no envolvimento dos cidadãos, que proponham uma nova cultura de direitos baseada na motivação e na co-participação da gestão ambiental (JACOBI, 2003, p.192).

Infelizmente não podemos acreditar que a transformação da sociedade se resume a uma consequência direta de atividades e currículos escolares apenas. E da forma como tem sido ensinado/aprendido tem contribuído muito pouco para qualquer mudança de mentalidade, hábito ou consciência.

\section{A ANTIPEDAGOGIA GOVERNAMENTAL}

Outro fator que poderia ser apontado como promotor do descolamento das propostas de educação ambiental presentes nas legislações, e teoricamente tratadas nas escolas, das práticas dos brasileiros de modo geral, é a postura antipedagógica adotada pelo próprio poder público em diversas situações, que acabam por deseducar a população. Poderíamos enumerar aqui diversas situações nas quais a temática ambiental é negligenciada pelo próprio poder público, mas vamos destacar apenas alguns casos.

Como exemplo, podemos mencionar a anistia dada às multas por desmatamentos ilegais (não importando a magnitude) realizados até 22 de julho de 2008 em todo o território nacional, concedida por ocasião da aprovação do Novo Código Florestal (Lei federal n¹2.651 de 25/05/2012). A destruição de milhões de hectares de matas ciliares, áreas de proteção permanente e reservas legais foi sumariamente perdoada. E, por outro lado, os proprietários de terras que cumpriram a legislação e não desmataram áreas legalmente protegidas não receberam qualquer incentivo.

Outro exemplo que pode ser lembrado é a postergação da desativação dos milhares de lixões espalhados pelo Brasil e a correta destinação dos resíduos sólidos gerados pelos brasileiros, previsto inicialmente para ocorrer em 2014, segundo a Política Nacional de Resíduos Sólidos (Lei federal n¹2.305 de 03/08/2010). A lei fala em prevenção e redução da geração de resíduos, tendo como proposta a prática de hábitos de consumo sustentável e um conjunto de instrumentos para propiciar o aumento da reciclagem e da reutilização dos resíduos sólidos e a destinação ambientalmente adequada dos rejeitos. Também institui a responsabilidade compartilhada dos 
geradores de resíduos: dos fabricantes, importadores, distribuidores, comerciantes, o cidadão e titulares de serviços de manejo dos resíduos sólidos urbanos na logística reversa dos resíduos e embalagens pré-consumo e pós-consumo.

No entanto, os quatro anos passados desde a aprovação da lei não foram suficientes para que os municípios se adequassem, então, elaborou-se um projeto de lei (Projeto de lei n²289/2015), já aprovado pelo Senado Federal e aguardando tramitação no Congresso Federal, que escalona as adequações dos municípios, conforme o número de habitantes, até o ano de 2021. Um problema de imensa magnitude ambiental e de saúde pública, que chegou com a crescente urbanização do país há quase quatro décadas, e que não encontra constrangimento de qualquer espécie para que sua solução seja adiada por mais de dez anos após sua aprovação.

Outro caso emblemático da antipedagogia do poder público brasileiro, que ajuda a apequenar o tema ambiental no entendimento da população brasileira em geral é o caso do desastre ambiental de Mariana-MG em 2015, considerado o pior da história do país (mesmo lembrando da experiência de Cubatão-SP, na década de 1980) em termos de degradação ambiental. Além das vítimas diretas e dos danos materiais causados a milhares de habitantes do médio e baixo Rio Doce, os danos ambientais são tão amplos e difusos que não puderam ser completamente mensurados até o presente momento ${ }^{5}$. Porém, até então, não houve o pagamento de qualquer uma das mais de vinte multas ambientais aplicadas pelo poder público à empresa responsável.

O exemplo mais recente de atitude deseducadora do ponto de vista ambiental adotada pelo poder público, foi a recente publicação de medida provisória (MP) que desonera investimentos em petróleo e gás (Medida provisória $n^{\circ} 795 / 17$ ), criando um regime especial para importação de bens a serem usados na exploração e desenvolvimento desses combustíveis fósseis. Esta Medida foi elaborada pelo mesmo governo que ratificou a participação do Brasil no Acordo de Paris (21ª Conferência das Partes da Convenção Quadro de Mudanças Climáticas da ONU) juntamente com todos os seus compromissos de redução de emissão de gases do efeito estufa, assumidos em 2016. Neste documento, o Congresso Brasileiro comprometeu o Brasil a reduzir as emissões em 37\% abaixo dos níveis de 2005, em 2025, com uma contribuição indicativa subsequente de reduzir as emissões em 43\% abaixo dos níveis de 2005, em 2030. Para isso, o país se comprometeu a aumentar a participação de bioenergia sustentável na sua matriz energética para aproximadamente 18\% até 2030, restaurar e reflorestar 12 milhões de hectares de florestas, bem como alcançar uma participação estimada de $45 \%$ de energias renováveis na composição da matriz energética em 2030. (BRASIL, 2015, p.01)

Como educar a população em geral, através de posturas incoerentes como estes exemplos ilustram? Mas há também outros fatores que podem colaborar para a falta de implementação da Política Nacional de Educação Ambiental e da observação de seus reflexos positivos na sociedade brasileira, como aqueles mencionados a seguir.

\section{CONFLITOS EPISTEMOLÓGICOS}

5 Publicado em: https://g1.globo.com/minas-gerais/desastre-ambiental-em mariana/noticia/apos-dois-anos-impacto-ambiental-dodesastre-em-mariana- ainda-nao-e-totalmente-conhecido.ghtml em 05/11/2017. 
No campo da Educação Ambiental existem alguns debates internos que acabam por se manifestar de uma forma ou de outra na elaboração ou na implementação das políticas públicas referentes ao tema e que, por vezes, atrapalham a obtenção de resultados.

Andrade et al (2014, p. 819) destacam a evidente evolução que a elaboração de políticas públicas voltadas para a Educação Ambiental no Brasil sofreram nas últimas décadas, tendo um ganho notável de organização, capaz de estabelecer parcerias não formais, gerando redes e programas de duração mais prolongadas. Mas, apesar desse claro avanço, é preciso melhorar, segundo os autores, no sentido de buscar maior abrangência e legitimidade nas diversas localidades, possibilitando o alcance dos diversos recortes territoriais aos quais essas políticas se destinam.

Eles destacam o ProNEA como uma experiência participativa e mobilizadora que, durante sua construção, em 2004, contou com a colaboração de mais de oitocentos educadores ambientais através de consulta pública, incorporando a preocupação com a presença de conteúdos inseridos no contexto local. Porém, a elaboração de Políticas Públicas não faz parte da formação desses educadores, dizem os autores, o que compromete a participação genuína destes atores e, consequentemente, geram conteúdos que não refletem de fato as questões locais. O resultado, segundo afirmam Andrade et al (2014, p.825), é a inexistência de políticas públicas de Educação Ambiental que tenham relevância para os atores de seu território de abrangência, evidenciando um distanciamento entre quem elabora as políticas e quem as executa e/ou recebe, mesmo tendo sido geradas através de metodologias e programas que permitem e estimulam a participação.

Segundo os autores:

Para a educação ambiental, as consequências [do distanciamento entre formuladores e executores das políticas públicas e seus beneficiários] são a criação de políticas que têm pouca legitimidade junto aos educadores ambientais do território, e com conteúdos que não são capazes de contemplar a sociobiodiversidade local, que não refletem o processo de sua construção e nem serão traduzidos nas ações que decorrem delas. (ANDRADE et al, 2014, p.825)

Há na realidade um embate entre pelo menos duas correntes teóricas que permeiam a elaboração das políticas públicas de Educação Ambiental no Brasil, através dos acadêmicos, educadores e técnicos envolvidos com o tema. Para Teixeira e Torales (2014, p.133), elas se diferenciam de acordo com a leitura da relação entre sociedade e natureza, sobre a crise ambiental e suas possíveis soluções, sobre visões de mundo e sua relação com a educação e suas respectivas abordagens metodológicas.

Há um grupo que acredita ser suficiente a adequação do modo de vida urbano consumista a práticas mais sustentáveis como a reciclagem e a reutilização dos materiais, a adoção de cultivos orgânicos, por exemplo, que naturalmente levariam à melhoria da qualidade de vida. Porém, há outra corrente que acredita ser insuficiente essa abordagem, e que a missão da Educação Ambiental é justamente questionar essa forma de organização da sociedade de consumo em massa e transformá-la em algo diferente, adotando uma postura mais crítica.

Inerente à questão ambiental, também estão as discussões entre as correntes preservacionista, que acredita na necessidade de delimitação de áreas protegidas destinadas exclusivamente aos animais e plantas em seu habitat natural, sem qualquer tipo de interação com seres humanos, e a corrente conservacionista, que acredita ser possível e até desejável a convivência 
de seres humanos e comunidades com a fauna e a flora protegidas. Ambas as vertentes estão presentes nas duas agências ambientais federais (IBAMA e ICMBIO) responsáveis pela implementação da Política Nacional de Educação Ambiental, juntamente com o Ministério da Educação.

Além destas divergências, as políticas públicas de Educação Ambiental brasileiras, assim, como todas as outras áreas, também sofrem com as descontinuidades e interrupções provocadas pelos interesses políticos dos governos, contribuindo também para sua perda de legitimidade e de efetividade. O exemplo mais notável, no caso da Educação Ambiental, ocorreu, segundo Loureiro et al (2013, p.60), com a interrupção dos programas e articulações governamentais em decorrência do desmembramento do Instituto Brasileiro de Meio Ambiente e dos Recursos Naturais Renováveis (IBAMA) que criou o Instituto Chico Mendes de Conservação da Biodiversidade (ICMBio) e extinguiu a então Coordenação Geral de Educação Ambiental (CGEAM/IBAMA), em 2007. A descentralização das atribuições de Educação Ambiental e a diminuição de recursos financeiros e humanos em ambas as instituições obrigaram uma reconstrução das articulações e debates internos sobre o papel da Educação Ambiental. Ao relatar um encontro entre funcionários dos dois órgãos governamentais, Loureiro et al (2013, p.64), descrevem que:

\footnotetext{
Evidenciava-se naquele encontro que a educação ambiental, estrategicamente posta para atuar no fortalecimento da gestão participativa, enfrentava dois focos de resistência, o primeiro representado pelo preservacionismo clássico, histórico e hegemônico na relação com áreas protegidas, que separa cultura e natureza, imputa à conservação da biodiversidade ausência de pessoas, além de um receituário de gestão técnico-científico. O segundo foco era, como apontado anteriormente, interno ao campo da educação ambiental e corporificado por tendências identificadas com a ação comunicativa e que abarcava uma multiplicidade de referências e intenções. (LOUREIRO et al, 2013, p.64)
}

Os autores concluem que essa falta de clareza institucional dificulta as estratégias que tentam elevar a Educação Ambiental ao posto de estratégia de participação social quando o assunto é conservação ambiental. o quadro institucional, portanto, contribui para a não implementação da Política Nacional de Educação Ambiental, que logo completará vinte anos.

\section{LICENCIATURAS E AMBIENTALIZAÇÃO CURRICULAR INSUFICIENTES}

Finalmente chegamos ao quarto fator de desconstrução dos princípios e práticas da Educação Ambiental no país. Lembramos que, mesmo com todas as dificuldades anteriormente apontadas, as políticas públicas ainda são as principais responsáveis pela adoção de práticas e introdução do tema da Educação Ambiental nos currículos de ensino em todo país, inclusive nas instituições de ensino superior. Porém, devemos lembrar que cada uma delas pode adotar uma dada perspectiva de Educação Ambiental (como vimos, não há unanimidade), e o ensino superior não é exceção.

A presença da Educação Ambiental nesse nível de ensino pode ser observada por dois ângulos distintos: o primeiro é a chamada ambientalização curricular, que, segundo Guerra \& Figueiredo (2014, p.111), “compreende a inserção de conhecimentos, de critérios e de valores sociais, éticos, estéticos e ambientais nos estudos e currículos universitários, no sentido de educar para a sustentabilidade socioambiental". Essa inserção pode ser observada em todas as esferas de atuação das instituições de ensino superior, que são ensino/pesquisa/extensão/gestão. O segundo é a 
observação da presença da temática ambiental no currículo propriamente dito das licenciaturas, pois seus egressos serão responsáveis pela sua transmissão e discussão em salas de aula de todos os ciclos de ensino da Educação Básica, em todo o território nacional.

Com relação ao primeiro aspecto, ao realizarem uma avaliação das instituiç̃oes de ensino superior vinculadas como instituições-elo da Rede Sul Brasileira de Educação Ambiental (REASul) e da Alianza de Redes Iberoamericanas por la Sustentabilidad y el Ambiente (ARIUSA), Guerra \& Figueiredo (2014, p.121) concluíram que:

(...), embora tenhamos avançado na dimensão da gestão ambiental para a sustentabilidade (...), quando se trata da ambientalização na organização curricular, depara-se com um hiato entre a efetiva inserção dessa temática nos documentos curriculares e nas práticas docentes e o que recomendam as Diretrizes Curriculares e as exigências do MEC-INEP para avaliação e recredenciamento dos cursos no que se refere à integração da Educação Ambiental nas disciplinas dos cursos de graduação 'de modo transversal, contínuo e permanente. (GUERRA \& FIGUEIREDO, 2014, p.121)

Em seguida, os autores apontam alguns fatores de mudança para uma melhor inserção e experiência da chamada ambientalização curricular nas instituições de ensino superior, como ir além dos currículos das diversas áreas do conhecimento e ser vivenciada como uma totalidade por todo o campus, e inclusive em atividades de extensão, espalhando-se também pela comunidade (KITZMANN \& ASMUS, 2012, p. 271). Este, para os autores, deve ser um processo contínuo e dinâmico, acompanhando os desafios ambientais colocados a todo instante à sociedade. E este processo, por sua vez, exige, segundo Guerra \& Figueiredo (2014, p.122), atributos e transformações nada triviais ou rápidas, como flexibilidade, diálogo de saberes, socialização de conhecimentos, mudança de atitudes e vivência de valores ambientais.

Lembramos, mais uma vez então, dos professores em sala de aula, a quem cabe essa árdua tarefa de transformação profunda e extremamente ampla de valores e mentalidade. Será que eles estão preparados para esse desafio? - foi a pergunta que Teixeira \& Torales (2014, p.127) fizeram. As autoras analisaram a estruturação dos cursos de licenciatura da Universidade Federal do Paraná (UFPR) quanto à sua ambientalização. Para elas,

Diante do avanço da educação ambiental na educação básica, o professor é colocado diante de exigências às quais ele responde com dificuldade e para as quais os cursos de licenciatura pouco contribuem. Certo distanciamento dos professores da educação ambiental tem como justificativa desde condições de trabalho que dificultam inovações e mais esforços, até a constatação de que não estão preparados para trabalhar com a educação ambiental. (TEIXEIRA \& TORALES, 2014, p.129)

Aqui, de novo nos deparamos com as diferentes abordagens epistemológicas adotadas, desta vez, nas instituições de ensino superior que, na maior parte das vezes, simplificam a complexidade da questão ambiental e suas reflexões, impossibilitando a concretização de seu potencial transformador (TEIXEIRA \& TORALES, 2014, p.129). E, consequentemente, comprometem a formação crítica dos futuros professores, no caso das licenciaturas, que não serão capazes de tratar o tema de maneira aprofundada nas salas de aula, geração após geração.

No caso da UFPR, por exemplo, as autoras encontraram maior expressão de ambientalização curricular nos cursos de bacharelado do que nas licenciaturas da universidade. Apenas cinco dos vinte e dois cursos de licenciatura têm em sua grade alguma disciplina sobre o tema 
Por um lado, supõe-se que o contato do licenciando com as disciplinas aqui analisadas é capaz de introduzi-lo nos fundamentos da educação ambiental, no caminho do potencial transformador que ela carrega. Em duas delas, isto se completa com a preocupação de tratar também a sua dimensão didático-pedagógica. Contudo, características como carga horária, o fato de ser disciplina tradicional e o perfil dos seus professores são, por outro lado, indícios de obstáculos da formação para a educação ambiental. (TEIXEIRA \& TORALES, 2014, p.141)

Ao analisarem os cursos de licenciatura da Universidade Federal de Santa Maria (UFSM), Boton et al (2010, p.47) observaram que apenas os cursos de Ciências Biológicas e de Geografia mencionam a variável ambiental no perfil do licenciado, pontuando de maneira genérica a necessidade de uma consciência socioambiental durante a atividade docente. Ambos os cursos oferecem em sua grade de disciplinas a Disciplina Complementar de Graduação em Educação Ambiental, mas de caráter opcional. Não há nenhuma disciplina curricular regular em Educação Ambiental em nenhuma das quinze licenciatura da UFSM.

Em termos de formação continuada de professores na mesma universidade, a Educação Ambiental poderia ser tratada no mestrado em Educação e/ou na especialização em Educação Ambiental, ofertados pela mesma instituição. Porém, segundo Boton et al (2010, p.47), na especialização observa-se uma tendência à ecologização do tema e a predominância de temas ligados ao meio ou às atividades rurais. Quanto ao mestrado, inexiste uma linha de pesquisa sobre o tema, que é muito pouco tratado nas pesquisas, limitando a difusão da Educação Ambiental junto à formação continuada de professores da UFSM.

Os autores concluem que:

A análise sobre a Educação Ambiental nos cursos de formação inicial e continuada de professores realizada na UFSM revelou este ser um tema precariamente abordado nos currículos, consoante com a realidade de diversas universidades em que a Educação Ambiental mais aparece como iniciativa pessoal de determinados professores, pondo em risco a meta da PNEA. (BOTON et al, 2010, p.48)

\section{CONSIDERAÇÕES FINAIS}

Apesar dos quatro fatores e dos problemas apontados, é através das políticas públicas que a Educação Ambiental consegue, a duras penas, se inserir, mesmo que parcialmente, nas dinâmicas de ensino em milhares de salas de aula espalhadas pelo país, pelo menos nos documentos oficiais das escolas e instituições de ensino públicas e privadas, como os Planos Políticos Pedagógicos (PPPs). E, segundo Andrade et al (2014, p.818), não há outra forma de enfrentar esta questão fora das políticas públicas.

Para Andrade \& Sorrentino (2013, p.215), considerando todo o tema que envolve a Educação Ambiental, a sua proximidade em relação aos processos de políticas públicas se justifica pela compreensão de que mesmo uma somatória de iniciativas educacionais desenvolvidas pela esfera privada não conseguirá reverter o grave quadro de degradação ambiental em que vivemos. Segundo os autores, é imprescindível a "incorporação da ação política para a formação de responsabilidade pelo planeta" (ANDRADE \& SORRENTINO, 2013, p.215). E essa ação política inclui participação e 
diálogo genuínos.

Para conseguirmos ter diálogo e participação, necessitamos, antes de mais nada, de começar a formar cidadãos de fato, conscientes de seus direitos mas também de seus deveres, não só para com as questões ambientais postas, mas de uma maneira mais abrangente. Leff $(2001$, p. 56$)$ fala sobre a impossibilidade de se resolver os crescentes e desafiadores problemas ambientais e reverter suas causas (se é que é possível) sem que haja uma mudança radical nos sistemas de conhecimento, dos valores e dos comportamentos gerados pela dinâmica de racionalidade existente, fundamentada no aspecto econômico do desenvolvimento.

No entanto, com o aparente esvaziamento das instâncias políticas de incentivo ao pensamento crítico, como as próprias políticas públicas, por exemplo, e seus canais de ação/comunicação com a sociedade, como a formação de professores ou as salas de aula, essa transformação radical de valores e comportamentos parece cada vez mais distante.

\section{REFERÊNCIAS BIBLIOGRÁFICAS}

ASSOCIAÇÃO BRASILEIRA DE EMPRESAS DE LIMPEZA PÚBLICA E RESÍDUOS ESPECIAIS. Panorama dos resíduos sólidos no Brasil. São Paulo, 2016.60p.

ANDRADE, Daniel Fonseca; DE LUCA, Andrea Quirino; CASTELLANO, Maria; RISSATO, Cíntia Guntzer; SORRENTINO, Marcos. Da pedagogia à política e da política à pedagogia: uma abordagem sobre a construção de políticas públicas em Educação Ambiental no Brasil. In: Ciência \& Educação, Bauru, v.20, n04, out-dez, pp.817-832, 2014.

ANDRADE, Daniel Fonseca; SORRENTINO, Marcos. Aproximando educadores ambientais de políticas públicas. In: SORRENTINO, Marcos et al (Ed.) Educação ambiental e políticas públicas: conceitos, fundamentos e vivências. Curitiba: Appris, 2013. pp. 215-223.

BOTOM, Jaiane de Moraes; COSTA, Ronaldo Gonçalves de Andrade; KURZMANN, Suzana Margarete; TERRAZAN, Eduardo A. O meio ambiente como conformação curricular na formação docente. In: Revista Ensaio, Belo Horizonte, v.12, n03, set-dez, pp. 41-50, 2010.

BRASIL. Constituição (1988). Constituição da República Federativa do Brasil, 3.ed. Brasília: Senado Federal, Centro Gráfico, 1988.

. Lei federal n 9.795, de 27 de Abril de 1999. Política Nacional de Educação Ambiental. Diário Oficial [da] República Federativa do Brasil, Poder Executivo, Brasília, DF, 28 abr. 1999. Seção 1, p.1.

. Programa Nacional de Educação Ambiental. Ministério do Meio Ambiente. Brasília, 2005. . Lei federal $\mathbf{n}^{\circ} \mathbf{1 2 . 3 0 5}$, de 02 de Agosto de 2010. Política Nacional de Resíduos Sólidos. Diário Oficial [da] República Federativa do Brasil, Poder Executivo, Brasília, DF, 03 ago. 2010. Seção 1, p.3.

BRASIL. Diretrizes Curriculares Nacionais para Educação Ambiental. Ministério da Educação. Brasília, 2012.

. Lei federal $\mathbf{n}^{\circ} \mathbf{1 2 . 6 5 1}$ de 25 de Maio de 2012. Dispõe sobre a proteção da vegetação nativa. Diário Oficial [da] República Federativa do Brasil, Poder Executivo, Brasília, DF, 28 mai. 2012. Seção 1, p.1.

. Plano Nacional de Educação (2014-2024). Ministério da Educação. Brasília, 2014.

Pretendida contribuição nacionalmente determinada para consecução do objetivo da

Convenção-Quadro das Nações Unidas sobre Mudança do Clima. Ministério do Meio Ambiente, Brasília, 2015.

. Medida provisória $\mathbf{n}^{\circ} \mathbf{7 9 5} / \mathbf{1 7}$, de 17 de agosto de 2017. Dispõe sobre o tratamento tributário das atividades de exploração e de desenvolvimento de campo de petróleo ou de gás natural e institui regime tributário especial para as atividades de exploração, desenvolvimento e produção de petróleo, de gás natural e de outros hidrocarbonetos fluidos. Diário Oficial [da] República Federativa do Brasil, Poder Executivo, Brasília, DF, 18 ago. 2017. Seção 1, p.2.

GUERRA, Antonio Fernando Silveira; FIGEIREDO, Mara Lúcia. Ambientalização curricular na Educação Superior: desafios e perspectivas. In: Educar em Revista, Curitiba, n03, pp. 109-126, 2014.

IINSTITUTO NACIONAL DE ESTUDOS E PESQUISAS EDUCACIONAIS ANÍSIO TEIXEIRA. Censo da Educação Superior. Brasília, 2017. 17p.

JACOBI, Pedro. Educação ambiental, cidadania e sustentabilidade. In: Cadernos de Pesquisa, São Paulo, 
n¹18, pp. 189-205, 2003.

LEFF, Enrique. Epistemologia ambiental. São Paulo: Cortez, 2001. 240p.

LOUREIRO, Carlos Frederico Bernardo; SAISSE, Maryane Vieira; CUNHA, Cláudia Conceição. Histórico da educação ambiental no âmbito federal da gestão ambiental pública: um panorama da divisão do IBAMA à sua reconstrução no ICMBIO. In: Desenvolvimento e Meio Ambiente, Curitiba, v.28, jul- dez, pp. 57-73, 2013.

KITZMANN, Dione; ASMUS, Milton. Ambientalização sistêmica - do currículo ao socioambiente. In: Currículo sem fronteiras, v.12, n01, jan-abr, pp. 269-290, 2012.

SILVA, Monica Ribeiro. Direito à educação, universalização e qualidade: cenários da Educação Básica e da particularidade do Ensino Médio. In: Jornal de Políticas Educacionais, vol.09, n 17/18, jan-jun/agodez, pp. 61-74, 2015.

TEIXEIRA, Cristina; TORALES, Marília Andrade. A questão ambiental e a formação de professores para a educação básica: um olhar sobre as licenciaturas. In: Educar em Revista, Curitiba, n03, pp. 127-144, 2014. TRAJBER, Rachel. Cidadania e consumo sustentável: nossas escolhas em ações conjuntas. In: MELLO, Soraia Silva; TRAJBER, Rachel (Orgs.). Vamos cuidar do Brasil - conceitos e práticas em Educação Ambiental na escola. Ministério da Educação. Brasília, 2007.

\section{SÍTIOS CONSULTADOS:}

INSTITUTO NACIONAL DE ESTUDOS E PESQUISAS EDUCACIONAIS ANÍSIO TEIXEIRA. Estatísticas da educação básica. Disponível em: <http://portal.inep.gov.br/sinopses-estatisticas-da-educacaobasica/>. Acesso em: 04 dez. 2017.

MINISTÉRIO DA EDUCAÇÃO. Seja um professor. Disponível em: $<$ http://sejaumprofessor.mec.gov.br/internas.php?area=como\&id=progIncentivo/>. Acesso em: 04 dez. 2017.

INSTITUTO NACIONAL DE PESQUISAS ESPACIAIS. Notícias. Disponível em: $<$ http://www.obt.inpe.br/OBT/noticias/INPE-estima-desmatamento-por-corte-raso-na-Amazoniaem-2017/>. Acesso em 06 dez. 2017.

$<$ http://www.inpe.br/queimadas/>. Acesso em 06 dez. 2017.

Queimadas. Disponível em:

MINISTÉRIO DO MEIO AMBIENTE. Convenção das Nações Unidas. Acordo de Paris. Disponível em: <http://www.mma.gov.br/clima/convencao-das-nacoes-unidas/acordo-de-paris/>. Acesso em: 08 dez. 2017.

PORTAL DE NOTÍCIAS G1 GLOBO. Brasil tem maior número de queimadas da história. Disponível em: <https://g1.globo.com/natureza/noticia/brasil-tem-mes-com-maior-numero-de-queimadas-dahistoria.ghtml>. Acesso em 09 dez. 2017.

Após dois anos impacto ambiental do desastre em Mariana ainda não é totalmente conhecido. Disponível em: <https://g1.globo.com/minas-gerais/desastreambiental-em mariana/noticia/apos-dois-anos-impacto-ambiental-do-desastre-em-mariana- aindanao-e-totalmente-conhecido.ghtml>. Acesso em 09 dez. 2017. 